\title{
Glioneuronal Tumors: Insights into a Rare Tumor Entity
}

\author{
Andra Valentina Krauze \\ Division of Radiation Oncology and Developmental Radiotherapeutics, BC Cancer Surrey, \\ University of British Columbia, Vancouver, Canada
}

Author for correspondence: Andra Valentina Krauze, Division of Radiation Oncology and Developmental Radiotherapeutics, BC Cancer Surrey, University of British Columbia, Vancouver, Canada. Email: andra.krauze@bccancer.bc.ca

Doi: https://doi.org/10.36255/exonpublications.gliomas.2021.chapter13

\begin{abstract}
Glioneuronal tumors are a group of rare neoplasms made up of neural and glial components in heterogenous proportions, generally exhibiting WHO grade I clinical behavior. These tumors affect infants, children and young adults, but are also described in adults and the elderly. They are strongly associated with seizures. Tumor subtypes described under the umbrella of glioneuronal tumors are actively evolving but to date comprise central, extraventricular and lipo- neurocytoma, desmoplastic infantile astrocytoma and ganglioglioma, diffuse leptomeningeal glioneuronal tumor, dysembryoplastic neuroepithelial tumor, papillary glioneuronal tumor, rosette-forming glioneuronal tumor of the fourth ventricle, rosetted glioneuronal tumor with neuropil-like islands, gangliocytoma, ganglioglioma, anaplastic ganglioglioma and paraganglioma. They vary in radiographic appearance, with some exhibiting large heterogenous solid/cystic masses. With large scale genetic and molecular analyses ongoing, classification continues to evolve. Seizure management and surgical resection represent the cornerstones of management, with the use of systemic agents and radiation lacking conclusive results. Optimal management requires multidisciplinary discussion including
\end{abstract}

In: Gliomas. Debinski W (Editor). Exon Publications, Brisbane, Australia. ISBN: 978-0-6450017-4-7; Doi: https://doi.org/10.36255/exonpublications.gliomas.2021

Copyright: The Authors.

License: This open access article is licenced under Creative Commons Attribution-NonCommercial 4.0 International (CC BY-NC 4.0) https://creativecommons.org/licenses/by-nc/4.0/ 
neuro-oncological and neuro-surgical expertise due to both the rarity of these tumors and the lack of evidence with data confined to small retrospective series and reviews.

Keywords: desmoplastic infantile astrocytoma and ganglioglioma; dysembryoplastic neuroepithelial tumor; glioneuronal tumors; neurocytoma; late effects

\section{INTRODUCTION}

Glioneuronal tumors are rare tumors comprised of both neural and glial components present in heterogenous proportions displaying indolent WHO grade I behavior (1-3). More recently, molecular characterization has allowed for more robust classification (4-9). The subtypes falling under the umbrella of glioneuronal tumors are actively evolving but currently include: central, extraventricular and lipo- neurocytoma; desmoplastic infantile astrocytoma and ganglioglioma (DIA/DIG), diffuse leptomeningeal glioneuronal tumor, dysembryoplastic neuroepithelial tumor (DNET), papillary glioneuronal tumor (PGNT), rosette-forming glioneuronal tumor of the fourth ventricle (RGNT), rosetted glioneuronal tumor with neuropil-like islands (GNTNI), gangliocytoma (GC), ganglioglioma (GG) and anaplastic ganglioglioma and paraganglioma $(1,2)$. Evolving entities including low grade neuroepithelial tumor of the young (9), multinodular and vacuolating neuronal tumor (10), and entities such as paraganglioma (11), are not described in detail in this chapter. Depending on the subtype, glioneuronal tumors can occur in all age groups. Most glioneuronal tumors present with seizures, depending on location and rate of growth. Patients can present with increased intracranial pressure, acute neurological deficits, hydrocephalus, diffuse leptomeningeal spread and symptoms of cord impingement or compression. Overall, the data surrounding glioneuronal tumors remains scant, largely comprised of small retrospective series and reviews of literature (1-3). Management involves seizure and symptom control, including resection when possible $(12,13)$. In sub-totally resected disease and recurrent or grade II/III tumors, adjuvant treatment in the form of radiation and or chemotherapy may be administered; however, data on improvements in outcome are lacking (14-21). Due to the indolent behavior of these tumors, late effects and survival are increasingly being examined (22-24).

\section{CLINICAL PRESENTATION}

Over $50 \%$ of patients present with headache (20), hydrocephalus $(21,25)$ and focal neurological deficits. Glioneuronal tumors are by far the most common histological type of brain tumors requiring surgery for epilepsy management (26) and are therefore part of the "low grade epilepsy associated neuroepithelial tumors" family (26-29). Patients can present with seizures in infancy, childhood or early adulthood and most patients will have a mean duration of epilepsy of approximately 5 years with a range of 0.1 to 35 years (8). A family history of seizures or brain tumors is not typically reported on history and most patients 
exhibit multiple seizure types with seizures that tend to be drug-resistant. About $42.9 \%$ of patients display two or more types of seizures with more patients presenting with complex partial seizures (dialeptic seizure, with vegetative or affective aura, psycho-sensorial aura and automatisms) or partial seizures evolving to secondarily generalized seizures (8). Temporal location is common, and the seizure presentation can be associated with focal cortical dysplasia (6). Although previous publications indicated a possible predilection for male (8) or female gender $(1,14,30)$, more recent data suggests a 1:1 distribution $(5,22)$. Age at presentation for DIA/DIG is infant to 33 years while for other types such as PGNT, RGNT and GNTNI, it is $12-70$ years $(7,8,20)$. In addition to seizures, patients can present with hydrocephalus $(21,25)$, increased intracranial pressure as well as focal neurological deficits depending on tumor location, rate of growth and age. DIA/DIG presents usually, although not exclusively, in infants with increasing head circumference and seizure (31). Most commonly, patients with low-grade tumors present with headache, nausea, vomiting, and seizure; less frequent presentations include neurological deficits, loss of consciousness and chronic intermittent microhemorrhages (32-34) (Table 1).

\section{Pathological, molecular and imaging features}

Glioneuronal tumors have been reported since 1910, with the number of publications growing in the last 10 years as the identification of molecular alterations has allowed for better differentiation of glioneuronal tumors from other similar tumors in differential diagnosis (Figure 1, Table 1). Previous limitations in diagnosis were related to limited ability to elicit radiographic differences, scant material for pathological analysis and the overall rarity of glioneuronal tumors. Ganglioglioma, paraganglioma, central neurocytoma and DNET have been reported on for some time (Figure 1) (1-3, 35-44). RGNT (39-41), PGNT $(42,43)$ and GNTNI (44) were added to the WHO classification in 2007 (1). In 2016, the classification

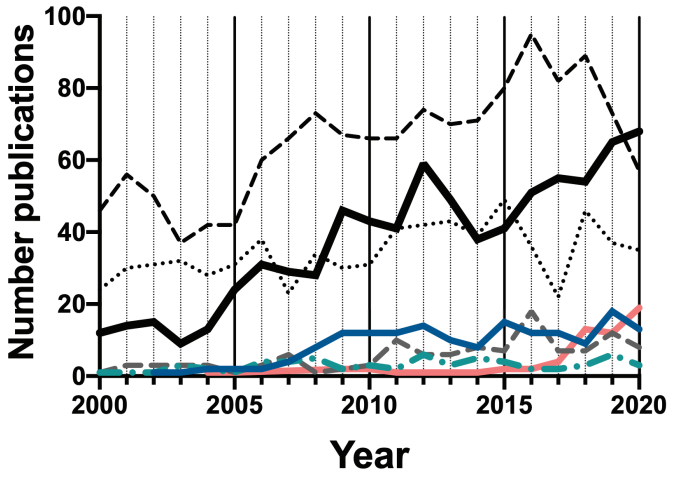

- Glioneuronal Tumors

-- Ganglioglioma

... Central Neurocytoma

- Rosette-forming glioneuronal tumor (RGNT)

-. Dysembryoplastic Neuroepithelial Tumor (DNET)

- Papillary glioneuronal tumor (PGNT)

- Diffuse leptomeningeal glioneuronal tumor (DLGNT)

Figure 1. Number of publications from 2000 to 2020 by major glioneuronal tumor histologies. Author's own analysis based on literature search information. Retrieved October to November 2020 from https://pubmed.ncbi.nlm.nih.gov/?term=glioneuronal+tumors\&sort=date (35). 


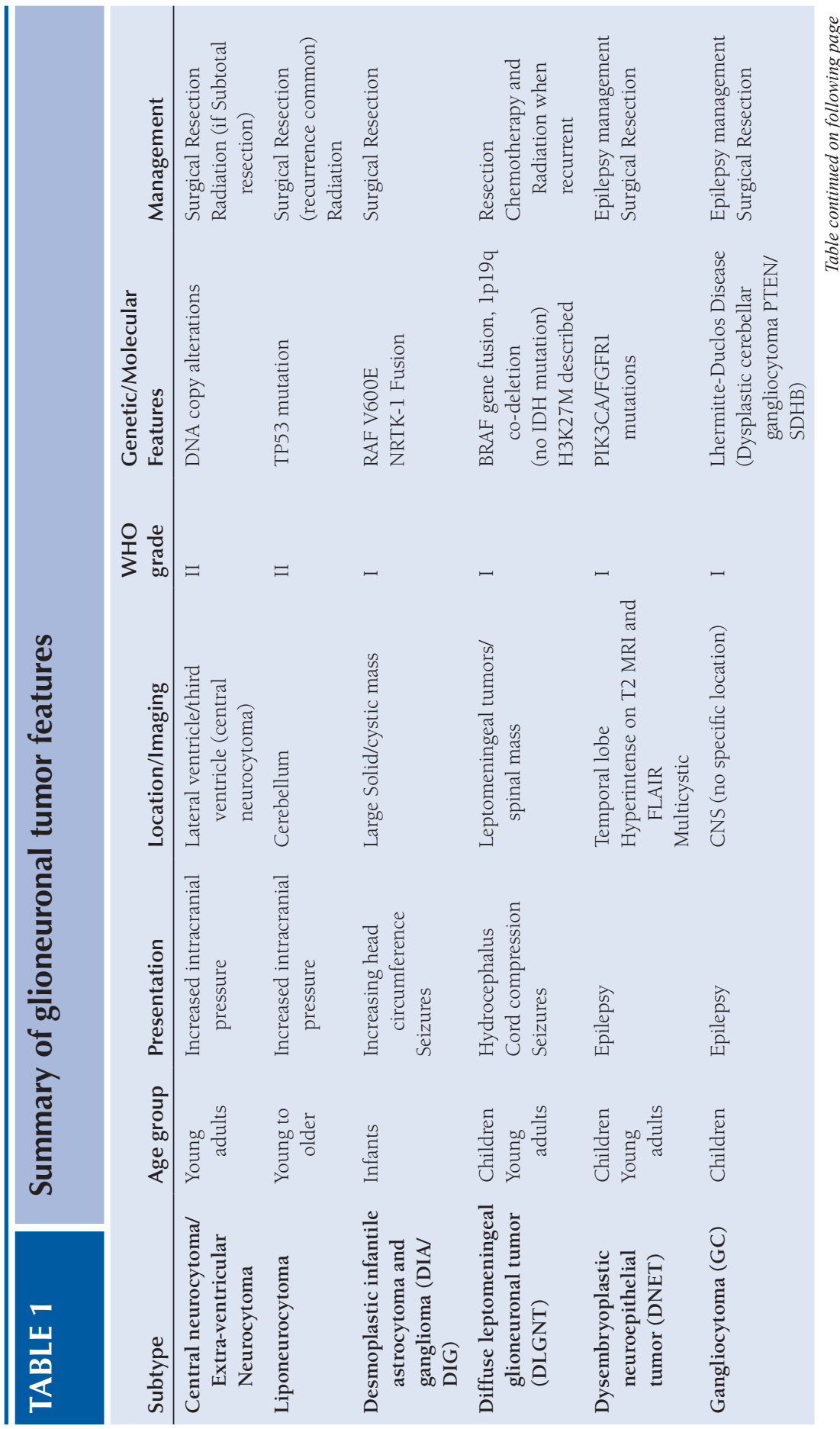




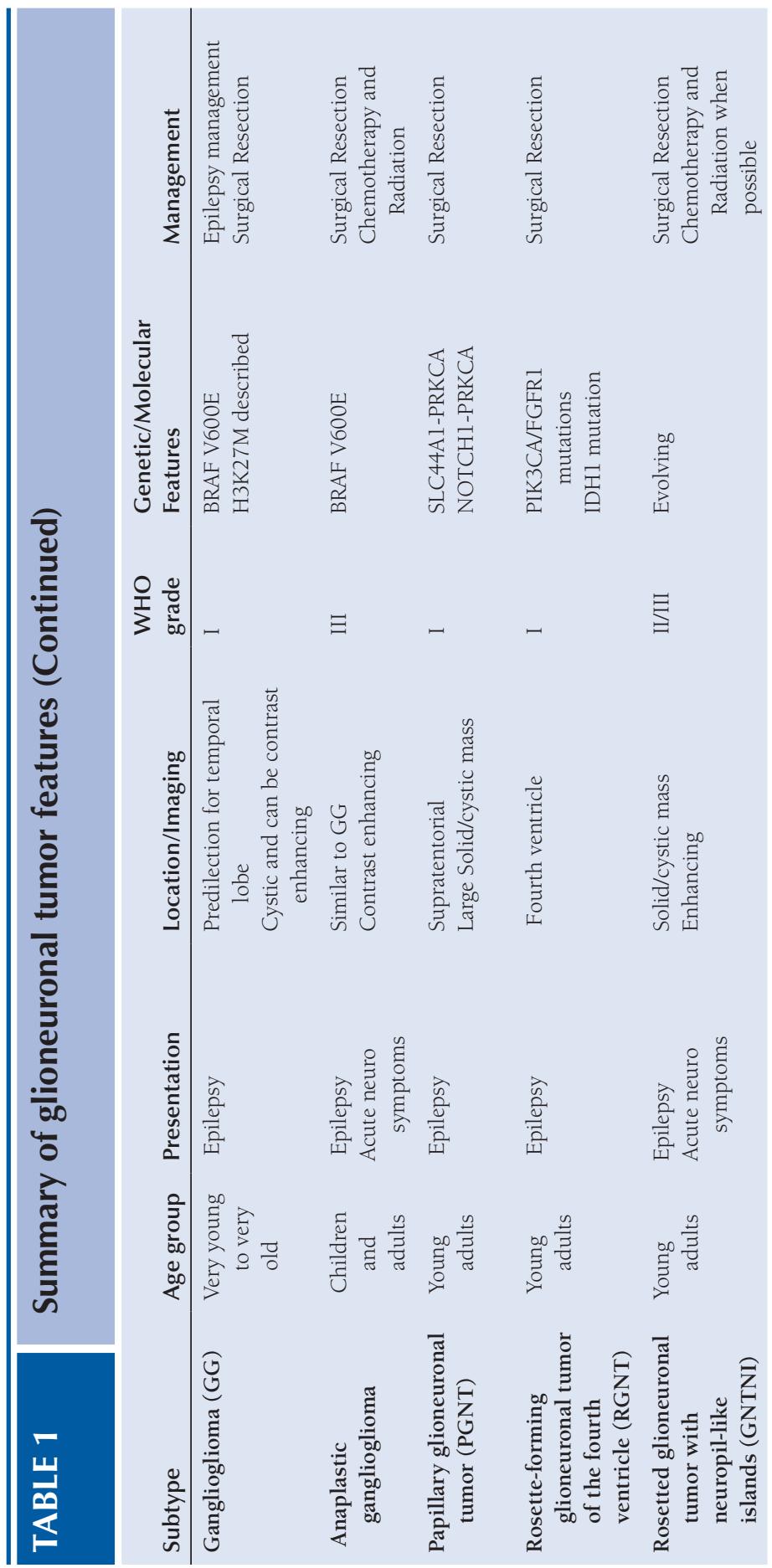


added diffuse leptomeningeal glioneuronal tumors (DLGNT) (1, 2, 45-51) where the number of published case reports, pathological studies and reviews has grown since (Figure 1) (35).

\section{Pathology}

The common feature of glioneuronal tumors is the presence of both glial and neuronal tissue as evidenced by glial fibrillary acid protein- positive cells and synaptophysin-positive neuronal cells forming solid areas (Figure 2A (52)). The rarity of PGNT (Figure 2A (52); 68 cases in literature), RGNT (Figure 2B (53); 130 cases in literature), ganglioglioma (Figure 2C (54); 1.3\% of all primary brain tumors), neurocytoma (Figure 2D (55); $0.1-0.5 \%$ of all brain tumors), makes diagnosis difficult (1-4). While each glioneuronal tumor can display certain distinct features (Figure 2), in some instances a tumor may demonstrate overlapping histologic features with mixed components (36) making diagnosis challenging. With the exception of central neurocytoma (WHO grade II), extraventricular neurocytoma (WHO grade II), liponeurocytoma (WHO grade II), GNTNI (WHO grade II/III) and anaplastic ganglioglioma (WHO grade III), glioneuronal tumors
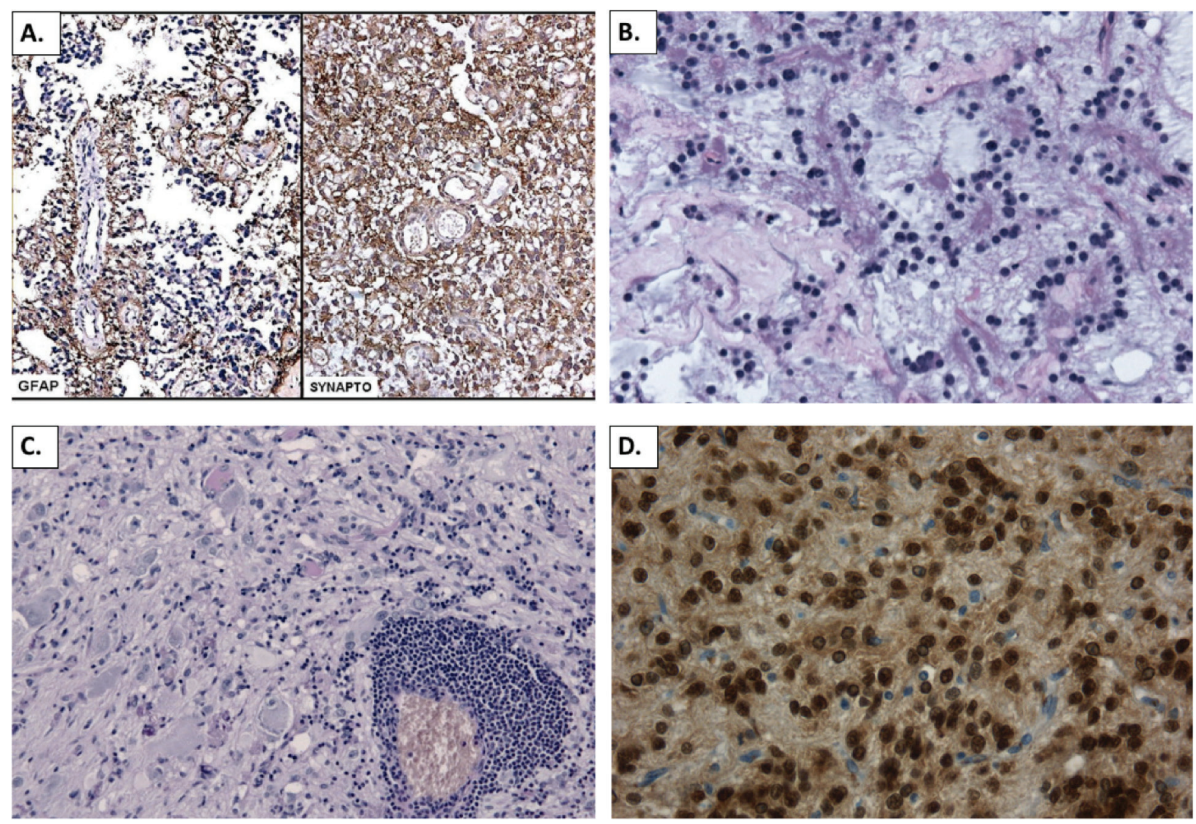

Figure 2. Pathologic features of glioneuronal tumors. A. Histopathology of papillary glioneuronal tumor (PGNT): the pseudopapillae formed by glial fibrillary acid protein (GFAP)positive cells and synaptophysin (SYNAPTO)-positive neuronal cells forming solid areas. (adapted from 52). B. Histopathology specimen (HE stain) of a RGNT (rosette-forming glioneuronal tumor; adapted from 53). C. PAS stain of a ganglioglioma displaying perivascular lymphocytic infiltrates and weakly PAS-positive eosinophilic granular bodies (x100 magnification; adapted from 54). D. Histopathology of Neurocytoma.

Immunohistochemistry for NeuN showing neuronal differentiation of tumor cells adapted from 55). 
exhibit WHO grade I behavior (Table 1). The Ki-67 labeling indices of most glioneuronal tumors are low, mostly $1-2 \%$ and generally less than $5 \%$; however, in PGNT, 13-14\% of total reported cases have shown increased proliferative indices $(1,34,42)$ in line with high grade gliomas (56-58). The pathology of glioneuronal tumors is complex, requiring significant neuropathological expertise for interpretation. Notably, unlike most other glioneuronal tumors, GNTNI and WHO grade III variants of GGs, such as anaplastic ganglioglioma and atypical neurocytoma behave more similar to other high-grade gliomas, also carrying a poorer prognosis. DLGNT was introduced in the $2016 \mathrm{WHO}$ classification of central nervous system tumors (1). A number of publications have since focused on this entity $(1,2,35,45-51,59)$ (Figure 1). DLGNT mainly occurs in children and is mostly characterized by leptomeningeal growth, although Appay et al. described cases that are neither diffuse nor leptomeningeal, concluding that DLGNT may represent a "spectrum that has yet to be fully clarified" (45). DNET is a benign, glioneuronal neoplasm also part of the differential for other glial tumors including glioma, ganglioglioma, pilocytic astrocytoma or diffuse astrocytoma $(4,5)$. DIA/DIG is under-represented in the literature, with fewer than 20 cases, it is present generally in infants less than 24 months and displays prominent desmoplasia (60-64) (Figure 3).

\section{Molecular characterization}

While the underlying biology for the different glioneuronal tumor subtypes remains unclear (4), large scale genomic and epigenomic analyses have provided more insight into genetic alterations (4-9). Data is still emerging but the rarity of glioneuronal tumors means it may take some years to fully explore. Stone et al. suggest that most glioneuronal tumors fall within two major groups: group 1 containing a higher proportion of tumors with a ganglioglioma-like appearance
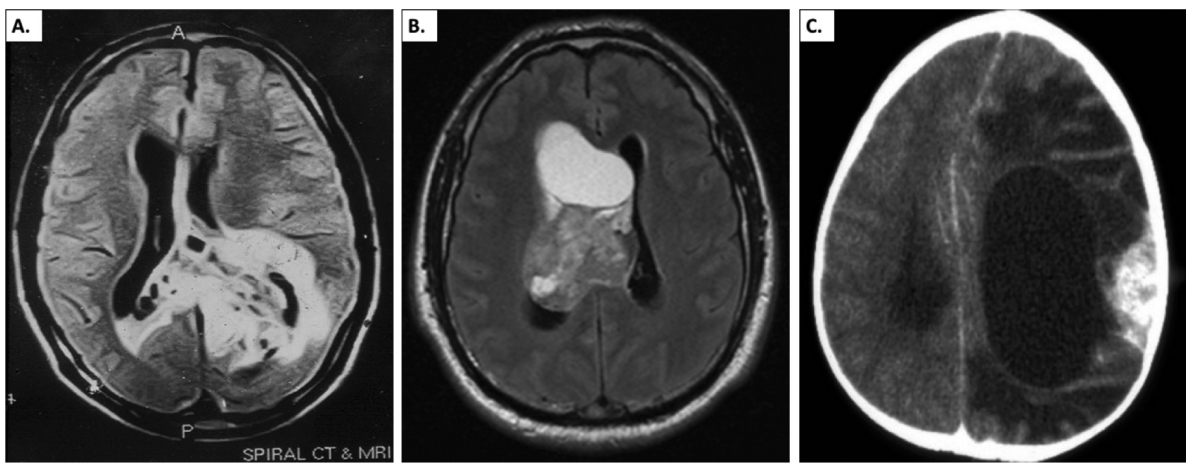

Figure 3. Radiographic appearance of glioneuronal tumors. A. Papillary glioneuronal tumor. Non-contrast magnetic resonance imaging showing hyper-intense lesion involving the left temporal and parieto-occipital regions. The tumor is crossing the midline to the right parietal region (adapted from 62). B. Axial FLAIR (fluid-attenuated inversion recovery) MR image showing a right ventricular mixed solid/cystic mass limited by the septum pellucidum and ventricular walls. With heterogeneous enhancement on post-gadolinium sequences.

Provisional diagnosis of central neurocytoma, later confirmed on pathology (adapted from 63).

C. Radiologic appearance of desmoplastic infantile ganglioglioma (adapted from 64). 
displaying more BRAF-V600E mutations while group 2 tumors are more DNETlike in appearance and display more FGFRl mutations (4). BRAF is an oncogene mutated in many malignancies and more recently described in one-third of GGs and $20-25 \%$ of DNET and DIA/DIG $(4,5,65,66)$. Some gliomas and glioneuronal tumors are characterized by a fusion between the BRAF gene and the locus KIAA1549 (45) (Table 1). The fusion causes a constitutional activation of the tyrosine kinase domain of BRAF and a permanent activation of the MAP kinase (MAPK) pathway $(6,66)$. The detection of a BRAF rearrangement can help distinguish cancers with favorable prognosis such as glioneuronal tumors from those with poorer prognosis, such as diffuse gliomas, including diffuse astrocytomas and oligodendrogliomas. It also has therapeutic implications, as targeted therapies against mutated BRAF-V600 protein are being developed (vemurafenib, dabrafenib) (67). BRAF V600E mutations were identified by DNA sequencing in 33\% of GGs and $27 \%$ of DNTs (8) and by immunohistochemistry in $29.5 \%$ of cases, $61.5 \%$ representing GG/GC/anaplastic ganglioglioma (5). Results can be discordant between immunohistochemistry and other molecular tests (5) illustrating the ongoing challenges in harnessing molecular testing for glioneuronal tumors and the as yet limited ability to draw conclusions with respect to diagnosis, prognosis and management. To date, the presence of BRAF mutation has not been associated with clinical presentation, imaging features or resolution of seizures postoperatively, acknowledging the limited data available. This is however evolving with recent descriptions of neuronal/glioneuronal tumors arising from the diencephalic region with a BRAF V600 mutation rate of $75 \%$ exhibiting clinically aggressive behavior (68). In pediatric GGs a worse recurrence-free survival of tumors with BRAF V600E mutation was reported by Dahiya et al. (69). Other identified mutations include PIK3CA (RGNTs and mixed RGNT/DNET) (69) with implications for targeting the PI3K/AKT/mTOR pathway (70,71), FGFRl mutations (20, 71-76), H3K27M-mutations (77, 78), SLC44A1-PRKCA and NOTCH1-PRKCA fusion (79), IDH1 mutation (80) and $1 p 19 q$ alterations $(78,81)$ (Table 1).

\section{Imaging Features}

The features of glioneuronal tumors on diagnostic imaging are highly variable. Limited data exists, hampering an in-depth analysis of radiographic-pathological correlation. Hybrid features have been noted in many tumors. In general, radiological studies acknowledge overlap of imaging features between glioneuronal tumors and other tumors, which complicates radiographic diagnosis (82). Large tumors demonstrate cystic degeneration and necrosis, hemorrhage, contrast enhancement, and regions of low apparent diffusion coefficient consistent with patterns seen with other high-grade pediatric brain tumors (83). Broadly, glioneuronal tumors are characterized by the presence of a solid/cystic mass in periventricular location with septations and a solid inner component (84) (Figure 3). Attempts have been made to radiographically classify long-term epilepsy-associated tumors, of which glioneuronal tumors form a significant component. A number of small series have described imaging features of PGNT (42, 85), RGNT (40, 41, 86), DLGNT (45-47, 87), GG (56), neurocytomas (16), DNT (8). PGNT, RGNT and GNTNI were added to the WHO classification in 2007 hence imaging reviews are more recent and evolving (2). Most of these tumors are located in the supratentorial region (69\%), however, spinal (23\%) and 
disseminated disease at primary diagnosis (8\%) are also described (7). They exhibit variable contrast enhancement with GNTNIs appearing mostly as solid tumors in $73 \%$ of cases; about 19\% appear as cystic with a mural nodule under T2-hyperintensity and T1-hypointensity (7) (Figure 3A (62)). The most common site of glioneuronal tumors is the temporal lobe followed by frontal lobe (8). Tumors with a high Ki-67 index ( $\geq 5)$ are more likely to exhibit perilesional edema and ring enhancement on magnetic resonance imaging (MRI) (10). DLGNT was added to the WHO classification in 2016 and publications have increased since $(1,2,45-50,55)$. In DLGNT, MRI is generally consistent with diffuse leptomeningeal enhancement predominantly and multiple cystic-solid lesions along the neural axis $(49,59,87)$ but may present more atypically as well $(45,88)$. GGs appear cystic-solid or solid with long T1 and T2 signals with associated calcification (89). Often there is limited edema, and they may display no or mild contrast enhancement. Neurocytomas can be ventricular or extraventricular. Extraventricular neurocytomas are usually cortically based and infiltrative without peritumoral edema or intratumoral hemorrhage (Figure 3B (63)). DIA/DIG on computed tomography and MRI appear as large superficial large cerebral masses with solid and cystic areas (60). The solid component of the tumor frequently shows contrast enhancement (60) (Figure 3C (64)). Ultimately, the differential diagnosis of these findings includes low-grade glioneuronal tumors and low-grade gliomas.

\section{MANAGEMENT, CLINICAL RESPONSE AND LATE EFFECTS}

Generally, surgical resection is the corner stone of seizure management for patients with glioneuronal tumors. The purpose of resection in glioneuronal tumors is twofold: to alleviate symptoms (secondary to CSF flow disruption, seizures and/ or increased intracranial pressure) and to achieve debulking in the context of more aggressive tumor subtypes $(13,26,90)$.

\section{Symptom control and surgical management}

Glioneuronal tumors presenting with hydrocephalus (DLGNT, RGNT) should be considered for urgent ventriculoperitoneal shunting surgery which can result in complete symptom resolution $(14,25,49)$. Surgical resection for debulking, and restoration of cerebrospinal fluid (CSF) flow when impeded, is the standard management $(12,25)$. Often the decision is made in multidisciplinary settings as these tumors are rare and the management is fraught with significant risks for late effects, particularly in patients with tumors that display more benign behavior who generally survive for longer. Several studies suggest that upwards of $70 \%$ of patients experience complete resolution of seizures post-operatively $(8,12,90)$. Prognosis can be good with a progression-free survival (PFS) in 85 to $95 \%$ of patients (12). Gross total resection (GTR) is superior to subtotal resection (STR) and tumors with a lower Ki-67 index and a lower WHO grade have a better prognosis as compared to those with higher index and higher grade $(7,12)$. Only about $50 \%$ of patients undergo GTR prompting the administration of adjuvant radiotherapy and chemotherapy in some patients although due to limited evidence the benefit thereof remains unclear $(18,20,40)$. 


\section{Systemic Management and Radiation Therapy}

Radiation therapy (RT) is generally considered for recurrent and higher-grade tumors such as neurocytoma, anaplastic ganglioglioma and GNTNI. Acharya et al. analyzed 150 patients with unresectable pediatric low-grade gliomas and glioneuronal tumors to identify prognostic features in patients treated with RT using clinicopathologic and molecular data (18). RPA (Recursive Partitioning Analysis) yielded low- and high-risk groups with 10-year overall survival (OS) of $95.6 \%$ versus $76.4 \%$. High-risk tumors included diffuse astrocytoma or location within thalamus/midbrain while low-risk tumors included pilocytic astrocytoma/ganglioglioma located outside of the thalamus/midbrain (18). The prognosis was independent of BRAF status but within the high-risk group, delayed RT (defined as RT after at least one line of chemotherapy), was associated with a further decrement in OS (18). The administration of chemotherapy is also heterogenous. Johnson et al. (16) carried out a comprehensive literature review of central neurocytoma regarding administration of chemotherapy. They identified 18 citations (39 cases of adult and pediatric central neurocytoma treated with chemotherapy) and found that nine patients with recurrent neurocytoma received temozolomide (TMZ) noting significant heterogeneity in chemotherapy administration (16). Chen et al. reported on long-term outcomes of 63 neurocytoma patients who received adjuvant radiotherapy after surgical resection (19). With a median follow-up of 69 months the 5-year OS and 5-year PFS were $94.4 \%$ and $95 \%$ after GTR + RT, 96.4\% and 100\% after STR + RT, and $100 \%$ and $90.9 \%$ after PR + RT (19). RT after incomplete resection led to OS and PFS comparable to those for GTR with excellent outcomes and limited late toxicity suggesting that adjuvant RT is a reasonable option for neurocytoma patients with incomplete resection. Radiosurgery as an alternative has also been proposed as an option with 5- and 10-year local tumor control rates 93\% and 87\%, respectively, and the 5- and 10-year PFS rates $89 \%$ and $80 \%$, respectively $(91,92)$. The use of chemotherapy, targeted agents, and Bevacizumab is only subject of case reports and small studies and benefit remains unclear (93-97). For disseminated, recurrent and high-grade disease, definitive radiotherapy or radiochemotherapy is considered and treatment may overall reflect that of other high-grade gliomas due to the histologic and natural history similarities they share $(7,17)$. Generally, the outcome in patients with glioneuronal tumors can be broadly discussed in the context of progression of disease, transformation to higher grade tumors and the long-term complications of treatment or late effects. In a series of patients treated at the St. Jude Children's Research Hospital (1986 to 2015), progression of disease and transformation to higher grade glioma accounted for $66 \%$ of the mortality (24). Other causes included secondary malignancy, shunt infection/sepsis, suicide and motor vehicle accidents (24). In this series, the median age at death for the cohort was 14.26 years (range, $0.58-32$ years), and the median time to death from diagnosis was 4.02 years (range, 0.21-24 years). Overall, our understanding of the optimal management and the outcomes of glioneuronal tumors remains limited due to the rarity of these tumors and the data originating from small series and literature reviews. With ongoing molecular characterization and the paralleled progress of targeted agents, data continues to evolve. 


\section{Late effects}

Despite more favorable survival outcomes as compared to other more aggressive gliomas, significant late effects are associated with glioneuronal tumors. Late effects are likely multifactorial, stemming from a combination of tumor presence, surgical resection, and adjuvant management including systemic agents and RT. The lack of data surrounding optimal management and outcomes also extends to lack of clarity surrounding the burden of late effects on patients with glioneuronal tumors. Ehrstedt et al. carried out a cross-sectional long-term follow-up evaluation on 28 children and adolescents (0-17.99 years), with a mean follow-up period of 12.1 years (23). They identified postoperative gain in cognitive function in seizurefree patients, but at a relatively low level, and high levels of anxiety and depression (23). In a series of 51 patients with low grade glioma and glioneuronal tumors managed at the St. Jude's Children's Research Hospital, USA, (1986 to 2015) with a mean age at diagnosis of 6.47 months (range, $0.17-11.76$ ) and mean duration of follow-up of 11.8 years, $96 \%$ of patients experienced at least one long-term deficit, such as endocrinopathy and obesity (51\%), neurological deficit and seizure (43\%), visual and hearing loss (56\%), neurocognitive impairment (49\%), cerebrovascular disease and scoliosis (27\%) and secondary malignancy (14\%) (24). Late effects correlated with tumor location (hypothalamic/optic pathway), administration of radiation therapy and more chemotherapy regimens (24). According to Upadhyaya et al., early psychological intervention should be included as part of the multidisciplinary management approach of children with both glioneuronal tumors and low-grade gliomas to reduce the risk of suicide in vulnerable subjects.

\section{CONCLUSION}

Glioneuronal tumors are uncommon tumors comprised of glial and neuronal components. They generally display indolent behavior but can behave aggressively. They are pathologically and radiographically complex, and classification hinges on advancements with respect to molecular analysis to allow for future personalized treatment which may improve outcomes. Currently, cases are best managed in multidisciplinary settings with the role of adjuvant treatment in the form of chemotherapy and radiation therapy beyond surgery remaining unclear. In depth counselling regarding late effects is paramount due to the burden of long-term life altering sequelae in long-term survivors. The creation of robust registries and tumor sequencing is imperative to allow for improvement of outcomes in the long term.

Conflict of Interest: The author declares no potential conflict of interest with respect to research, authorship and/or publication of this chapter.

Copyright and permission statement: The author confirms that the materials included in this chapter do not violate copyright laws. Where relevant, appropriate permissions have been obtained from the original copyright holder(s), and all original sources have been appropriately acknowledged or referenced. 


\section{REFERENCES}

1. Louis DN, Ohgaki H, Wiestler OD, Cavenee WK, Burger PC, Jouvet A, et al. The 2007 WHO classification of tumours of the central nervous system. Acta Neuropathol. 2007;114(2):97-109. https:// doi.org/10.1007/s00401-007-0243-4

2. Wen PY, Huse JT. 2016 World Health Organization classification of central nervous system tumors. Continuum. Neuro-oncology. 2017;23(6):1531-47. https://doi.org/10.1212/ CON.0000000000000536

3. Franceschi E, Frappaz D, Rudà R, Hau P, Preusser M, Houillier C, et al. EURACAN Domain 10. Rare Primary Central Nervous System Tumors in Adults: An Overview. Front Oncol. 2020;10:996. https:// doi.org/10.3389/fonc.2020.00996

4. Stone TJ, Keeley A, Virasami A, Harkness W, Tisdall M, Izquierdo Delgado E, et al. Comprehensive molecular characterisation of epilepsy-associated glioneuronal tumours. Acta Neuropathol. 2018;135(1):115-29. https://doi.org/10.1007/s00401-017-1773-z

5. Breton Q, Plouhinec H, Prunier-Mirebeau D, Boisselier B, Michalak S, Menei P, et al. BRAFV600E immunohistochemistry in a large series of glial and glial-neuronal tumors. Brain Behav. 2017;7(3):e00641. https://doi.org/10.1002/brb3.641

6. Srinivasa K, Cross KA, Dahiya S. BRAF Alteration in Central and Peripheral Nervous System Tumors. Front Oncol. 2020;10:574974. https://doi.org/10.3389/fonc.2020.574974

7. Schlamann A, von Bueren AO, Hagel C, Zwiener I, Seidel C, Kortmann RD et al. An individual patient data meta-analysis on characteristics and outcome of patients with papillary glioneuronal tumor, rosette glioneuronal tumor with neuropil-like islands and rosette forming glioneuronal tumor of the fourth ventricle. PLoS One. 2014;9(7):e101211. https://doi.org/10.1371/journal.pone.0101211

8. Zhang YX, Shen $\mathrm{CH}$, Guo Y, Zheng Y, Zhu JM, Ding Y, et al. BRAF V600E mutation in epilepsyassociated glioneuronal tumors: Prevalence and correlation with clinical features in a Chinese population. Seizure. 2017;45:102-6. https://doi.org/10.1016/j.seizure.2016.12.004

9. Huse JT, Snuderl M, Jones DT, Brathwaite CD, Altman N, Lavi E, et al. Polymorphous low-grade neuroepithelial tumor of the young (PLNTY): an epileptogenic neoplasm with oligodendroglioma-like components, aberrant CD34 expression, and genetic alterations involving the MAP kinase pathway. Acta Neuropathol. 2017;133(3):417-29. https://doi.org/10.1007/s00401-016-1639-9

10. Alizada O, Ayman T, Akgun MY, Sar M, Urganci N, Kemerdere R. Multinodular and vacuolating neuronal tumor of the cerebrum: Two cases and review of the literature.Clin Neurol Neurosurg. 2020;197:106149. https://doi.org/10.1016/j.clineuro.2020.106149

11. Schweizer L, Thierfelder F, Thomas C, Soschinski P, Suwala A, Stichel D, et al. Molecular characterization of CNS paragangliomas identifies cauda equina paragangliomas as a distinct tumor entity. Acta Neuropathol. 2020;140(6):893-906. https://doi.org/10.1007/s00401-020-02218-7

12. Ahmed AK, Dawood HY, Gerard J, Smith TR. Surgical Resection and Cellular Proliferation Index Predict Prognosis for Patients with Papillary Glioneuronal Tumor: Systematic Review and Pooled Analysis. World Neurosurg. 2017;107:534-541. https://doi.org/10.1016/j.wneu.2017.08.041

13. Ranger A, Diosy D. Seizures in children with dysembryoplastic neuroepithelial tumors of the brain--A review of surgical outcomes across several studies. Childs Nerv Syst. 2015; 31:847-55 https://doi. org/10.1007/s00381-015-2675-9

14. Mahavadi AK, Temmins C, Patel MR, Singh H. Supratentorial intraventricular rosette-forming glioneuronal tumors - Case report and review of treatment paradigms. Surg Neurol Int. 2020;11:138 https://doi.org/10.25259/SNI_188_2019

15. Chen J, Dahiya SM. Update on Circumscribed Gliomas and Glioneuronal Tumors. Surg Pathol Clin. 2020;13(2):249-66. https://doi.org/10.1016/j.path.2020.02.004

16. Johnson MO, Kirkpatrick JP, Patel MP, Desjardins A, Randazzo DM, Friedman HS, et al. The role of chemotherapy in the treatment of central neurocytoma. CNS Oncol. 2019;8(3):CNS41. https://doi. org/10.2217/cns-2019-0012

17. Rades D, Zwick L, Leppert J, Bonsanto MM, Tronnier V, Dunst J, et al. The role of postoperative radiotherapy for the treatment of gangliogliomas. Cancer. 2010;116:432-42. https://doi.org/10.1002/ cncr.24716 
18. Acharya S, Liu JF, Tatevossian RG, Chiang J, Qaddoumi I, Gajjar A, et al. Risk stratification in pediatric low-grade glioma and glioneuronal tumor treated with radiation therapy: an integrated clinicopathologic and molecular analysis. Neuro Oncol. 2020;22(8):1203-13. https://doi.org/10.1093/neuonc/ noaa031

19. Chen Y, Li WB, Feng J, Qiu X. Long-term outcomes of adjuvant radiotherapy after surgical resection of central neurocytoma. Radiat Oncol. 2014; 9: 242. https://doi.org/10.1186/ s13014-014-0242-2

20. Wilson CP, Chakraborty AR, Pelargos PE, Shi HH, Milton CK, Sung S, et al. Rosette-forming glioneuronal tumor: an illustrative case and a systematic review. Neurooncol Adv. 2020;2(1):vdaal16. https:// doi.org/10.1093/noajnl/vdaal16

21. Gosal JS, Tiwari S, Garg M, Bhaskar S, Jha DK. Letter to "Diffuse leptomeningeal glioneuronal tumour (DLGNT) with hydrocephalus as an initial symptom: a case-based update". Childs Nerv Syst. 2020;36(7):1341. https://doi.org/10.1007/s00381-020-04610-w

22. Faramand AM, Barnes N, Harrison S, Gunny R, Jacques T, Tahir MZ, et al. Seizure and cognitive outcomes after resection of glioneuronal tumors in children. Epilepsia. 2018;59(1):170-78. https://doi. org/10.1111/epi.13961

23. Ehrstedt C, Rydell AM, Gabert Hallsten M, Strömberg B, Ahlsten G. Cognition, health-related quality of life, and mood in children and young adults diagnosed with a glioneuronal tumor in childhood. Epilepsy Behav. 2018;83:59-66. https://doi.org/10.1016/j.yebeh.2018.03.026

24. Liu APY, Hastings C, Wu S, Bass JK, Heitzer AM, Ashford J, et al. Treatment burden and long-term health deficits of patients with low-grade gliomas or glioneuronal tumors diagnosed during the first year of life. Cancer. 2019;125(7):1163-75. https://doi.org/10.1002/cncr.31918

25. Chen W, Kong Z, Fu J, Zhao D, Wang R, Ma W, et al. Diffuse leptomeningeal glioneuronal tumour (DLGNT) with hydrocephalus as an initial symptom: a case based update. Childs Nerv Syst. 2020;36(3):459-68. https://doi.org/10.1007/s00381-019-04481-w

26. Blümcke I, Aronica E, Urbach H, Alexopoulos A, Gonzalez-Martinez JA. A neuropathology-based approach to epilepsy surgery in brain tumors and proposal for a new terminology use for long-term epilepsy-associated brain tumors. Acta Neuropathol 2014;128(1):39-54. https://doi.org/10.1007/ s00401-014-1288-9

27. Mehrotra A, Singh S, Kanjilal S, Kumar A, Pal L, Mathur V, et al. Long-Term Epilepsy-Associated Tumors (LEATs): A Single-Center, Retrospective Series and Review of Literature on Factors Affecting the Seizure Outcome. World Neurosurg. 2020; 144; el49-e155. https://doi.org/10.1016/j. wneu.2020.08.036

28. Slegers RJ, Blumcke I. Low-grade developmental and epilepsy associated brain tumors: a critical update 2020. Acta Neuropathol Commun. 2020;8(1):27. https://doi.org/10.1186/s40478-020-00904-x

29. Halfpenny A, Ferris SP, Grafe M, Woltjer R, Selden N, Nazemi K, et al. A case of recurrent epilepsyassociated rosette-forming glioneuronal tumor with anaplastic transformation in the absence of therapy. Neuropathology. 2019;39(5):389-393. https://doi.org/10.1111/neup.12586

30. Komori T, Scheithauer BW, Hirose T. A rosette-forming glioneuronal tumor of the fourth ventricle: infratentorial form of dysembryoplastic neuroepithelial tumor? Am J Surg Pathol. 2002;26(5): 582-591. https://doi.org/10.1097/00000478-200205000-00004

31. Li Z, Yu Y, Lu Z, Gong J. Infantile and Noninfantile Desmoplastic Astrocytoma and Ganglioglioma: Only Different Age of Onset? World Neurosurg. 2020;144:e189-e194. https://doi.org/10.1016/j. wneu.2020.08.091

32. Tavallaii A, Keykhosravi E, Rezaee H. Acute presentation of papillary glioneuronal tumor due to intratumoral hemorrhage in a toddler: an odd presentation of a rare pathology. Br J Neurosurg. 2020:1-6. https://doi.org/10.1080/02688697.2020.1800588

33. Lu Q, Zou LP, Gui QP, Shi XY, Zhai X, Yang G, et al. Diffuse Leptomeningeal Glioneuronal Tumor Presented with Language Developmental Delay. Neuro Endocrinol Lett. 2019;40(4):161-165.

34. Bourekas EC, Bell SD, Ladwig NR, Gandhe AR, Shilo K, McGregor JM, et al. Anaplastic papillary glioneuronal tumor with extraneural metastases. J Neuropathol Exp Neurol. 2014;73(5):474-6. https:// doi.org/10.1097/NEN.0000000000000061

35. Krauze AV. Own analysis based on literature search information. Retrieved October to November 2020 from https://pubmed.ncbi.nlm.nih.gov/?term=glioneuronal+tumors\&sort=date 
36. Harrison W, Elsamadicy AA, McMahon JT, Chagoya G, Sobel RA, McLendon RE, et al. Glioneuronal Tumor With Features of Ganglioglioma and Neurocytoma Arising in the Fourth Ventricle: A Report of 2 Unusual Cases and a Review of infratentorial Gangliogliomas. J Neuropathol Exp Neurol. 2019;78(9):780-87. https://doi.org/10.1093/jnen/nlz060

37. Tish S, Habboub G, Jones J, Ostrom QT, Kruchko C, Barnholtz-Sloan JS, et al. The epidemiology of central and extraventricular neurocytoma in the United States between 2006 and 2014. J Neurooncol. 2019;143(1):123-27. https://doi.org/10.1007/s11060-019-03144-9

38. Sander C, Wallenborn M, Brandt VP, Ahnert P, Reuschel V, Eisenlöffel C, et al. Central neurocytoma: SNP array analyses, subtel FISH, and review of the literature. Pathol Res Pract. 2019;215(7):152397. https://doi.org/10.1016/j.prp.2019.03.025

39. Al Krinawe Y, Esmaeilzadeh M, Hartmann C, Krauss JK, Hermann EJ. Pediatric rosette-forming glioneuronal tumor of the septum pellucidum. Childs Nerv Syst. 2020;36(11):2867-70. https://doi. org/10.1007/s00381-020-04575-w

40. Choque Cuba B, Ortega Zufiría JM, Poveda Núñez PD, Lomillos Prieto N, Sierra Rodríguez M, Tamarit Degenhardt $\mathrm{M}$, et al. Rosette-forming glioneuronal tumor of the fourth ventricle. Two cases report and literature review. Neurocirugia. 2018;29(5):255-9. https://doi.org/10.1016/j.neucir.2017.12.001

41. Morris C, Prudowsky ZD, Shetty V, Geller T, Elbabaa SK, Guzman M, et al. Rosette-Forming Glioneuronal Tumor of the Fourth Ventricle in Children: Case Report and Literature Review. World Neurosurg. 2017;107:1045.e9-1045.e16. https://doi.org/10.1016/j.wneu.2017.07.150

42. Zhao RJ, Zhang XL, Chu SG, Zhang M, Kong LF, Wang Y. Clinicopathologic and neuroradiologic studies of papillary glioneuronal tumors. Acta Neurochir. 2016;158(4):695-702. https://doi.org/10.1007/ s00701-016-2744-1

43. Carangelo B, Arrigucci U, Mariottini A, Lavalle L, Muscas G, Branco D, et al. Papillary glioneuronal tumor: case report and review of literature. G Chir. 2015;36(2):63-9. https://doi.org/10.11138/ gchir/2015.36.2.063

44. Giunti L, Buccoliero AM, Pantaleo M, Lucchesi M, Provenzano A, Palazzo V, et al. Molecular characterization of paediatric glioneuronal tumours with neuropil-like islands: a genome-wide copy number analysis. Am J Cancer Res. 2016;6(12):2910-18.

45. Appay R, Pages M, Colin C, Jones DTW, Varlet P, Figarella-Branger D. Diffuse leptomeningeal glioneuronal tumor: a double misnomer? A report of two cases. Acta Neuropathol Commun. 2020;8(1):95. https://doi.org/10.1186/s40478-020-00978-7

46. Xu H, Chen F, Zhu H, Luo L, Zhang R. Correction to: Diffuse leptomeningeal glioneuronal tumor in a Chinese adult: a novel case report and review of literature. Acta Neurol Belg. 2020;120(6):1501. https://doi.org/10.1007/s13760-020-01278-6

47. Abongwa C, Cotter J, Tamrazi B, Dhall G, Davidson T, Margol A. Primary diffuse leptomeningeal glioneuronal tumors of the central nervous system: Report of three cases and review of literature. Pediatr Hematol Oncol. 2020;37(3):248-58. https://doi.org/10.1080/08880018.2019.1711270

48. Tiwari S, Yadav T, Pamnani J, Mathew JM, Elhence P, Praneeth K, et al. Diffuse Leptomeningeal Glioneuronal Tumor: A Unique Leptomeningeal Tumor Entity. World Neurosurg. 2020;135:297-300. https://doi.org/10.1016/j.wneu.2019.12.119

49. Sáez-Alegre M, Saceda Gutiérrez JM, Utrilla Contreras C, Aracil Santos FJ, García-Feijoo P, Carceller Benito F. Diffuse leptomeninges al glioneuronal tumour: where to biopsy? Case report and literature review. Childs Nerv Syst. 2020. https://doi.org/10.1007/s00381-020-04955-2

50. Lyle MR, Dolia JN, Fratkin J, Nichols TA, Herrington BL. Newly Identified Characteristics and Suggestions for Diagnosis and Treatment of Diffuse Leptomeningeal Glioneuronal/Neuroepithelial Tumors: A Case Report and Review of the Literature. Child Neurol Open. 2015;2(1):2329048X14567531. https://doi. org/10.1177/2329048X14567531

51. Deng MY, Sill M, Chiang J, Schittenhelm J, Ebinger M, Schuhmann MU, et al. Molecularly defined diffuse leptomeningeal glioneuronal tumor (DLGNT) comprises two subgroups with distinct clinical and genetic features. Acta Neuropathol. 2018;136(2):239-53. https://doi.org/10.1007/ s00401-018-1865-4

52. Radotra BD, Kumar Y, Bhatia A, Mohindra S. Papillary glioneuronal tumor: a new entity awaiting inclusion in WHO classification. Diagn Pathol. 2, 6. 2007. Retrieved November 24, 2020, from https:// commons.wikimedia.org/wiki/File:Pgnt_immuno.jpg. https://doi.org/10.1186/1746-1596-2-6 
53. Jensflorian. Histopathology specimen (HE stain) of a RGNT (rosette-forming glioneuronal tumor).2013. Retrieved November 24, 2020, from https://commons.wikimedia.org/wiki/File:RGNT_ HE_2.jpg

54. Jensflorian. PAS stain of a ganglioglioma displaying perivascular lymphocytic infiltrates and weakly PAS-positive eosinophilic granular bodies (x100 magnification). 2010. Retrieved November 24, 2020, from https://commons.wikimedia.org/wiki/File:Ganglioglioma_lymphocytic_cuffing_PAS.jpg

55. Marvin 101. Histopathology of Neurocytoma. Immunohistochemistry for NeuN showing neuronal differentiation of tumor cells. 2009. Retrieved November 24, 2020, from https://commons. wikimedia. org/wiki/File:Neurocytoma_NeuN.jpg

56. Kawataki T, Sato E, Sato T, Kinouchi H. Anaplastic ganglioglioma with malignant features in both neuronal and glial components-case report. Neurol Med Chir. 2010; 50:228-31. https://doi.org/10.2176/ nmc. 50.228

57. Liu L, Narayan P, Xiong J, Xiong Z. Anaplastic glioneuronal tumor with KIAA1549/BRAF fusion. Intractable Rare Dis Res. 2019;8(4):279-82. https://doi.org/10.5582/irdr.2019.01118

58. Luyken C, Blumcke I, Fimmers R, Urbach H, Wiestler OD, Schramm J. Supratentorial gangliogliomas: histopatho-logic grading and tumor recurrence in 184 patients with a median follow-up of 8 years. Cancer. 2004; 101:146-55. https://doi.org/10.1002/cncr.20332

59. Lakhani DA, Mankad K, Chhabda S, Feizi P, Patel R, Sarma A, et al. Diffuse Leptomeningeal Glioneuronal Tumor of Childhood. Am J Neuroradiol. 2020. https://doi.org/10.3174/ajnr.A6737

60. Per H, Kontaş O, Kumandaş S, Kurtsoy A. A report of a desmoplastic non-infantile ganglioglioma in a 6-year-old boy with review of the literature. Neurosurg Rev. 2009;32:369-74. https://doi.org/10.1007/ s10143-009-0195-3

61. Geramizadeh B, Kamgarpour A, Moradi A. Desmoplastic infantile ganglioglioma: Report of a case and review of the literature.J Pediatr Neurosci. 2010; 5(1): 42-4. https://doi.org/10.4103/1817-1745.66669

62. Radotra BD, Kumar Y, Bhatia A, Mohindra S. Papillary glioneuronal tumor: a new entity awaiting inclusion in WHO classification. Diagn Pathol. 2, 6. 2007. Retrieved November 24, 2020, from https://commons.wikimedia.org/wiki/File:Papillary_glioneuronal_tumor.jpg

63. Dawes L. Radiopaedia. 2008. Retrieved November 24, 2020, from https://commons.wikimedia.org/ wiki/File:Central_neurocytoma.jpg

64. Fadare O, Mariappan MR, Hileeto D, Zieske AW, Kim JH, Ocal IT. Desmoplastic Infantile Ganglioglioma: cytologic findings and differential diagnosis on aspiration material. Cytojournal. 2005;2(1):1. Retrieved November 24, 2020, from https://commons.wikimedia.org/wiki/File:Desmoplastic_infantile_ ganglioglioma.jpg

65. Blessing MM, Blackburn PR, Krishnan C, Harrod VL, Barr Fritcher EG, Zysk CD, et al. Desmoplastic infantile Ganglioglioma: a MAPK pathway-driven and microglia/macrophage-rich Neuroepithelial tumor. J Neuropathol Exp Neurol. 2019;78(11):1011-21. https://doi.org/10.1093/jnen/nlz086

66. Roth JJ, Santi M, Pollock AN, Harding BN, Rorke-Adams LB, Tooke LS, et al. Chromosome band 7q34 deletions resulting in KIAA1549-BRAF and FAM131B-BRAF fusions in pediatric low-grade Gliomas. Brain Pathol. 2015;25(2):182-92. https://doi.org/10.1111/bpa.12167

67. Hertzman Johansson, C. \& Egyhazi Brage, S. BRAF inhibitors in cancer therapy. Pharmacol Ther. 2014;142(2):176-82. https://doi.org/10.1016/j.pharmthera.2013.11.011

68. Ho CY, Bornhorst M, Almira-Suarez MI, Donev K, Grafe M, Gordish-Dressman H, et al. Clinicopathologic Features of Diencephalic Neuronal and Glioneuronal Tumors. J Neuropathol Exp Neurol. 2020;79(1):67-73. https://doi.org/10.1093/jnen/nlz115

69. Dahiya S, Haydon DH, Alvarado D, Gurnett CA, Gutmann DH, Leonard JR. BRAF(V600E) mutation is a negative prognosticator in pediatric ganglioglioma. Acta Neuropathol. 2013;125(6):901-10. https://doi.org/10.1007/s00401-013-1120-y

70. Eye PG, Davidson L, Malafronte PJ, Cantrell S, Theeler BJ. PIK3CA mutation in a mixed dysembryoplastic neuroepithelial tumor and rosette forming glioneuronal tumor, a case report and literature review. J Neurol Sci. 2017;373:280-4. https://doi.org/10.1016/j.jns.2016.11.003

71. Sievers P, Appay R, Schrimpf D, Stichel D, Reuss DE, Wefers AK, et al. Rosette-forming glioneuronal tumors share a distinct DNA methylation profile and mutations in FGFRl, with recurrent comutation of PIK3CA and NF1. Acta Neuropathol. 2019;138(3):497-504. https://doi.org/10.1007/ s00401-019-02038-4 
72. Bale TA. FGFR- gene family alterations in low-grade neuroepithelial tumors. Acta Neuropathol Commun. 2020;8(1):21. https://doi.org/10.1186/s40478-020-00898-6

73. Yamada S, Nobusawa S, Yamazaki T, Teranishi T, Watanabe S, Murayama K, et al. An epilepsyassociated glioneuronal tumor with mixed morphology harboring FGFRl mutation. Pathol Int. 2019;69(6):372-77. https://doi.org/10.1111/pin.12799

74. Qaddoumi I, Orisme W, Wen J, Santiago T, Gupta K, Dalton JD et al. Genetic alterations in uncommon low-grade neuroepithelial tumors: BRAF, FGFRl, and MYB mutations occur at high frequency and align with morphology. Acta Neuropathol. 2016;131:833-45. https://doi.org/10.1007/ s00401-016-1539-z

75. Rivera B, Gayden T, Carrot-Zhang J, Nadaf J, Boshari T, Faury D et al. Germline and somatic FGFRI abnormalities in dysembryoplastic neuroepithelial tumors. Acta Neuropathol. 2016;131:847-63. https://doi.org/10.1007/s00401-016-1549-x

76. Lucas CG, Gupta R, Doo P, Lee JC, Cadwell CR, Ramani B, et al. Comprehensive analysis of diverse low-grade neuroepithelial tumors with FGFRl alterations reveals a distinct molecular signature of rosette-forming glioneuronal tumor. Acta Neuropathol Commun. 2020;8(1):151.

77. Navarro RE, Golub D, Hill T, McQuinn MW, William C, Zagzag D, et al. Pediatric midline H3K27Mmutant tumor with disseminated leptomeningeal disease and glioneuronal features: case report and literature review. Childs Nerv Syst.2020. https://doi.org/10.1007/s00381-020-04892-0

78. Nambirajan A, Suri V, Kedia S, Goyal K, Malgulwar PB, Khanna G, et al. Paediatric diffuse leptomeningeal tumor with glial and neuronal differentiation harbouring chromosome $1 \mathrm{p} / 19 \mathrm{q}$ co-deletion and H3.3 K27M mutation: unusual molecular profile and its therapeutic implications. Brain Tumor Pathol. 2018;35(3):186-91. https://doi.org/10.1007/s10014-018-0325-0

79. Hou Y, Pinheiro J, Sahm F, Reuss DE, Schrimpf D, Stichel D, et al. Papillary glioneuronal tumor (PGNT) exhibits a characteristic methylation profile and fusions involving PRKCA. Acta Neuropathol. 2019;137(5):837-46.

80. Jayapalan RR, Mun KS, Wong KT, Sia SF. Malignant Transformation of a Rosette-Forming Glioneuronal Tumor with IDH1 Mutation: A Case Report and Literature Review. World Neurosurg X. 2019;2:100006. https://doi.org/10.1016/j.wnsx.2018.100006

81. Chiang J, Dalton J, Upadhyaya SA, Patay Z, Qaddoumi I, Li X, et al. Chromosome arm lq gain is an adverse prognostic factor in localized and diffuse leptomeningeal glioneuronal tumors with BRAF gene fusion and lp deletion. Acta Neuropathol. 2019;137(1):179-81. https://doi.org/10.1007/ s00401-018-1940-x

82. Demir MK, Yapıcıer O, Yılmaz B, Kılıç T. Magnetic resonance imaging findings of mixed neuronalglial tumors with pathologic correlation: a review. Acta Neurol Belg. 2018;118(3):379-86. https://doi. org/10.1007/s13760-018-0981-1

83. Orman G, Mohammed S, Tran HDB, Lin FY, Meoded A, Desai N, et al. Neuroimaging Appearance of Cerebral Malignant Epithelioid Glioneuronal Tumors in Children. Am J Neuroradiol. 2020;41(9):1740-44. https://doi.org/10.3174/ajnr.A6668

84. Abdel Razek AAK, Elsebaie NA, Zamora C, Castillo M. Imaging of Neuronal and Mixed Glioneuronal Tumors. J Comput Assist Tomogr. 2020;44(3):356-69. https://doi.org/10.1097/ RCT.0000000000001010

85. Tan W, Huang W, Xiong J, Pan J, Geng D, Jun Z. Neuroradiological features of papillary glioneuronal tumor: a study of 8 cases. J Comput Assist Tomogr. 2014;38(5):634-8. https://doi.org/10.1097/ RCT.0000000000000109

86. Gao L, Han F, Jin Y, Xiong J, Lv Y, Yao Z, et al. Imaging features of rosette-forming glioneuronal tumours. Clin Radiol. 2018;73(3):275-82. https://doi.org/10.1016/j.crad.2017.10.011

87. Ghoniya R, Raheja A. Imaging in diffuse leptomeningeal glioneuronal tumor. Neurol India. 2019;67(2):615-6. https://doi.org/10.4103/0028-3886.258051

88. Tiwari N, Tamrazi B, Robison N, Krieger M, Ji J, Tian D. Unusual radiological and histological presentation of a diffuse leptomeningeal glioneuronal tumor (DLGNT) in a 13-year-old girl. Childs Nerv Syst. 2019;35(9):1609-14. https://doi.org/10.1007/s00381-019-04074-7

89. Pujadas E, Chen L, Rodriguez FJ. Pathologic and molecular aspects of anaplasia in circumscribed gliomas and glioneuronal tumors. Brain Tumor Pathol. 2019;36(2):40-51. https://doi.org/10.1007/ s10014-019-00336-z 
90. Giulioni M, Marucci G, Cossu M, Tassi L, Bramerio M, Barba C, et al. CD34 Expression in LowGrade Epilepsy-Associated Tumors: Relationships with Clinicopathologic Features. World Neurosurg. 2019;121:e761-e768. https://doi.org/10.1016/j.wneu.2018.09.212

91. Nakamura A, Kano H, Niranjan A, Lunsford LD. Radiosurgery for Central Neurocytoma. Prog Neurol Surg. 2019;34:232-37. https://doi.org/10.1159/000493069

92. Hung YC, Lee CC, Yang HC, Mohammed N, Kearns KN, Sun SB, et al. Stereotactic radiosurgery for central neurocytomas: an international multicenter retrospective cohort study. J Neurosurg. 2020;1-10. https://doi.org/10.3171/2020.1.JNS191515

93. Pellerino A, Rudà R, Bertero L, Magistrello M, Franchino F, Cassoni P, et al. Successful use of bevacizumab in an adult primary diffuse leptomeningeal glioneuronal tumor. J Neurosurg Sci. 2018;62(2):229-32.

94. Valiakhmetova A, Papusha L, Druy A, Yasko L, Ektova A, Karachunsky A, et al. Pediatric diffuse leptomeningeal glioneuronal tumor: Two clinical cases of successful targeted therapy. Pediatr Blood Cancer. 2020;67(12):e28478. https://doi.org/10.1002/pbc.28478

95. Alvarez-Breckenridge C, Miller JJ, Nayyar N, Gill CM, Kaneb A, D'Andrea M, et al. Clinical and radiographic response following targeting of BCAN-NTRK1 fusion in glioneuronal tumor. NPJ Precis Oncol. 2017;1(1):5. https://doi.org/10.1038/s41698-017-0009-y

96. Dodgshun AJ, SantaCruz N, Hwang J, Ramkissoon SH, Malkin H, Bergthold G, et al. Disseminated glioneuronal tumors occurring in childhood: treatment outcomes and BRAF alterations including V600E mutation. J Neurooncol. 2016;128(2):293-302. https://doi.org/10.1007/s11060-016-2109-x

97. Aguilera D, Castellino RC, Janss A, Schniederjan M, McNall R, MacDonald Mazewski C. Clinical responses of patients with diffuse leptomeningeal glioneuronal tumors to chemotherapy. Childs Nerv Syst. 2018;34(2):329-34. https://doi.org/10.1007/s00381-017-3584-x 
